\title{
Estudio de la instigación social en un modelo de agresión inducida por aislamiento: efectos de la administración de JNJ16259685, un antagonista de receptores $\mathrm{mGlu} 1^{*}$
}

\author{
Study of the Social Instigation in a Model of Isolation- \\ Induced Aggression: Effects of JNJ16259685 \\ Administration, an mGlu1 Receptor Antagonist
}

Recibido: mayo 2 de 2013 | Revisado: enero 14 de 2014 | Aceptado: enero 14 de 2014

\author{
MERCEDes MARTÍN-LÓPEZ** \\ SARA INFANTE *** \\ MARÍA CAVAS \\ José Francisco NAVARro \\ Universidad de Málaga, España
}

doi:10.11144/Javeriana.UPSY13-3.eism

Para citar este artículo: Martín-López, M., Infante, S., Cavas, M. \& Navarro, J. F. (2014). Estudio de la instigación social en un modelo de agresión inducida por aislamiento: efectos de la administración de JNJ16259685, un antagonista de receptores mGlu1. Universitas Psychologica, 13(3), 1027-1036. http:// dx.doi.org/10.11144/Javeriana.UPSY13-3.eism

Artículo de investigación

** Facultad de Psicología. Profesora Titular de Psicobiología, Dpto. Psicobiología y Metodología de las Ciencias del Comportamiento. Correo electrónico: mmmartin@uma.es

**** Universidad de Málaga, España. Correos electrónicos: sara_molinero2005@hotmail.com, mariacavas@uma.es,navahuma@uma.es

\section{RESUMEN}

La instigación social intensifica la conducta agresiva permitiendo observar niveles más extremos de agresión. Estudios recientes indican que el receptor metabotrópico del glutamato mGlu1 está implicado en la regulación de la conducta agresiva en un modelo de agresión inducida por aislamiento. El objetivo de este trabajo fue evaluar los efectos de la administración de un antagonista del receptor mGlu1 (JNJ16259685) sobre la conducta agresiva normal e intensificada, utilizando instigación social en un modelo animal de agresión inducida por aislamiento. Varios grupos de animales aislados fueron expuestos a 5 minutos de instigación social, recibiendo la mitad de ellos JNJ16259685 (0.5 mg/kg, ip) o vehículo. Las interacciones agonísticas de 10 min de duración se realizaron en un área neutral 30 min después de la inyección. Dichos encuentros fueron grabados en vídeo para el posterior análisis etológico de diez categorías conductuales. La instigación redujo la latencia de ataque y aumentó la frecuencia y duración de los ataques frente a los animales no instigados. La administración de JNJ16259685 redujo de forma significativa la conducta agresiva en ambos casos, sugiriendo la implicación del receptor mGlu1 en la modulación de la agresión normal e intensificada. Palabras clave

Agresión; agresión patológica; instigación social; modelo animal; glutamato; JNJ16259685; mGlu1

\section{A B S T R A C T}

Social instigation intensifies aggressive behavior in rodents allowing observe more extreme levels of aggression. Recent studies indicate that glutamate metabotropic receptor 1 (mGlu1) are involved in the regulation of aggressive behavior in isolation-induced aggression model. The object of this work was to examine social instigation in an animal model of isolation-induced aggression and assess the anti-aggressive effects of an mGlu1 receptor antagonist (JNJ16259685) on normal and heightened aggressive behavior. Several groups of individually housed mice were exposed to 5 minutes of social instigation, and half of them received an acute administration of JNJ16259685 $(0.5 \mathrm{mg} / \mathrm{kg}$, ip) or vehicle. Ten minute of dyadic interactions were staged between a singly housed and an anosmic mouse in a neutral area $30 \mathrm{~min}$ after drug or vehicle administration. The encounters were videotaped for subsequent analysis 
of ten ethological behavioural categories. Social instigation reduced latency of attack and increased the frequency and duration of attacks against not instigated animals. JNJ16259685 administration significantly reduced aggressive behavior in both cases, suggesting the involvement of mGlu1 receptor in the modulation of normal and heightened aggression. Keywords

aggression; pathological aggression; social instigation; animal models; glutamate; JNJ16259685; mGlu1

El estudio de la neurobiología de la agresión ha ido evolucionando en los últimos tiempos, desde el empleo de modelos animales clásicos que permiten observar la conducta agresiva normal o adaptada para la supervivencia, hacia la búsqueda de modelos que posibiliten reproducir niveles muy altos de agresión, en un intento por aumentar el valor traslacional de estos estudios, aproximándolos a la agresión extrema o violenta observada en humanos (Miczek, de Boer \& Haller, 2013). Se trata de incitar la aparición de conductas agresivas consideradas patológicas o anormales, ya sea por aspectos cuantitativos (reducción de la latencia de ataque, así como un aumento del tiempo y frecuencia de estas conductas) como cualitativos (dirigidas a zonas vulnerables del oponente, por resultar desproporcionada o por producirse fuera de contexto), que presenta ciertas similitudes con la violencia en humanos y ofrece la oportunidad de probar tratamientos más adecuados para la agresión patológica (Antúnez, Martín-López \& Navarro, 2011; Comai, Tau, Pavlovic \& Gobbi, 2012; Fish, Faccimodo \& Miczek, 1999).

Uno de estos procedimientos es el conocido como instigación social, provocación o "primming", que consiste en exponer al animal experimental, en su propia jaula, a un potencial rival que está protegido en un cilindro perforado de plástico o de alambre, durante un corto periodo de tiempo antes de la confrontación real. La exposición a la visión, olor y ruidos del potencial oponente constituye una provocación a la que los ratones machos responden generando más del doble de ataques y amenazas en los encuentros posteriores (De Almeida \& Miczek, 2002; Fish et al., 1999; Kudryavtseva, 1991). Este efecto ha sido observado también en peces, ratas y hámsters (Fish et al., 1999; Potegal \& Ten- brink, 1984). Además, la instigación incrementa de forma específica las conductas agresivas, sin afectar a las conductas locomotoras, de ingesta o sexuales, persistiendo altos niveles de agresión tiempo después de haber retirado el estímulo provocador, probablemente debido a un aumento en el "arousal agresivo" o "tendencia al ataque" (Potegal, 1992; Potegal \& Tenbrink, 1984). En este modelo han sido probados fundamentalmente compuestos serotoninérgicos que actúan sobre los receptores 5-HT1A y 5-HT1B (Centenaro et al., 2008; Da Veiga, Miczek, Lucion \& De Almeida, 2011; De Almeida \& Miczek, 2002).

Además de la serotonina, otros sistemas de neurotransmisión han sido implicados en la regulación de la agresión como el GABA (MartínLópez \& Navarro, 2002, 2009) y el glutamato (Navarro, De Castro \& Martín-López, 2010), entre otros. El glutamato es el principal neurotransmisor excitador del sistema nervioso central y actúa sobre sus receptores ionotrópicos postsinápticos (NMDA, AMPA y kainato) y sobre los receptores metabotrópicos (mGlu) que modulan su liberación, la respuesta postsináptica y la actividad de otras sinapsis. La mayoría de los estudios se han centrado en el papel de los receptores NMDA y AMPA en la agresión, aunque a veces los resultados han sido contradictorios (Belozertseva \& Bespalov, 1999; Miczek \& Haney, 1994; Musty \& Consroe, 1982; Vekovischeva et al., 2004; Vekovischeva, Aitta-aho, Verbitskaya, Sandnabba \& Korpi, 2007). En este sentido, el topiramato, cuyo mecanismo de acción implica (al menos parcialmente) la modulación de los receptores AMPA, ha demostrado reducir la agresión en modelos animales (Navarro, Burón \& Martín-López, 2007) y en humanos (Comai et al., 2012). Recientemente, Newman et al. (2012) han sugerido un papel relevante para el glutamato en la intensificación de la agresión producida por la ingesta de alcohol, ya sea mediante el bloqueo directo del receptor NMDA o bien por la posible acción moduladora que sobre ellos ejercen los receptores mGlu5.

La implicación de los receptores metabotrópicos del glutamato en la agresión es menos conocida. En nuestro laboratorio, empleando el 
modelo de agresión inducida por aislamiento, hemos comprobado que la administración aguda de antagonistas selectivos de los receptores mGlu5 (MPEP; 5-25mg/kg, ip) y mGlu1 (JNJ16259685; $0.125-8 \mathrm{mg} / \mathrm{kg}$, ip) produce una potente reducción de las conductas ofensivas (amenaza y ataque), sin afectar a la motilidad (Navarro, De Castro \& Martín-López, 2008; Navarro, Postigo, Martín \& Burón, 2006). Se ha descrito también la posible participación en la regulación de la agresión los receptores mGlu2/3 (LY379268 y LY354740) y mGlu7 (AMN082) (De Castro, Martín-López \& Navarro, 2010; Navarro, De Castro \& MartínLópez, 2009; Navarro, Luque \& Martín-López, 2009). Asimismo, en el modelo de residenteintruso, se ha observado una acción antiagresiva inespecífica, con el bloqueo de los receptores mGlu2/3 (LY379268) y más específica con un antagonista del receptor mGlu5 (MTEP), siendo igualmente efectivos reduciendo la agresión cuando se incorpora el procedimiento de instigación social (Newman et al., 2012).

El receptor mGlu1 se expresa en estructuras cerebrales implicadas en la regulación de la conducta agresiva como el hipotálamo, amígdala, sustancia gris periacueductal, septum lateral y neocorteza (Ferraguti \& Shigemoto, 2006; Lavreysen, Nóbrega, Leysen, Langlois \& Lesage, 2004), y la acción antagonista el compuesto JNJ16259685 $(0.125-8 \mathrm{mg} / \mathrm{kg})$ ha mostrado una drástica y específica reducción de la conducta agresiva en el modelo de agresión inducida por aislamiento (Navarro et al., 2008). Sin embargo, no se ha probado la eficacia de este compuesto en formas de agresión más extremas.

El objetivo de este estudio es doble: por un lado, comprobar si la instigación social puede intensificar la agresión conseguida en el modelo clásico de agresión inducida por aislamiento y, por otro lado, poner a prueba la eficacia antiagresiva del compuesto JNJ6259685 (antagonista de los receptores mGlu1) en formas aumentadas de agresión para explorar el papel del receptor mGlu1 en la modulación de la agresión normal y patológica. Que se tenga conocimiento, es la primera investigación que pone a prueba ambos objetivos.

\section{Método}

Se utilizaron un total de 146 ratones albinos machos adultos de la cepa Swiss OF.1 (Harlam Ibérica, Barcelona), con un peso de entre 25 y $30 \mathrm{~g}$ a la llegada al laboratorio. Fueron agrupados de cinco en cinco, durante siete días, y posteriormente asignados de forma aleatoria a dos condiciones de alojamiento. 59 ratones fueron empleados como animales experimentales y controles, siendo alojados individualmente en jaulas de plástico transparentes $(24 \times 13.5 \times 13 \mathrm{~cm})$ durante un periodo de aislamiento de treinta días. Y el resto permaneció alojado en grupos de cinco, para ser empleados como oponentes "anósmicos" ( $\mathrm{n}=59)$ o como animales "instigadores" ( $\mathrm{n}=28)$. Para todos los animales la comida y bebida se administró "ad libitum". Las condiciones ambientales del laboratorio fueron cuidadosamente controladas, manteniéndose el ciclo de luz/oscuridad (luz: 20:00-8:00h) y una temperatura $\left(20^{\circ} \mathrm{C}\right)$ y humedad constantes.

Este experimento se ha realizado de acuerdo con las principales reglas de cuidado y uso de Animales de Laboratorio aprobado por el Consejo Directivo de las Comunidades Europeas del 24 de Noviembre de 1986 (86/609/EEC).

\section{Administración del fármaco}

El JNJ6259685 fue adquirido comercialmente (laboratorios Tocris) y disuelto en solución salina (90\%) más DMSO (10\%). Para este estudio, se empleó una única dosis de $0.5 \mathrm{mg} / \mathrm{kg}$, elegida con base en los resultados obtenidos en nuestro laboratorio (Navarro et al., 2008).

Los animales aislados fueron asignados de forma aleatoria a cuatro grupos: dos grupos vehículos que recibieron solución salina al 90 \% y DMSO al $10 \%$ y otros dos tratados con una dosis de $0.5 \mathrm{mg} /$ $\mathrm{kg}$ de JNJ6259685. En todos los casos, la administración se realizó por vía intraperitoneal (ip) y de forma proporcional al peso del animal (volumen constante de $10 \mathrm{ml} / \mathrm{kg}$ ), 30 minutos antes de la prueba conductual. 


\section{Modelo de agresión inducida por aislamiento y descripción de la anosmia}

El protocolo seguido para inducir agresión por aislamiento fue el mismo descrito por Brain, McAllister y Walmsey (1989). Consiguiendo que tras 30 días de aislamiento los animales aislados muestren conductas de amenaza y ataque dirigidas hacia el oponente anósmico, mientras que este no ataca y adopta posturas defensivas. Asimismo, la anosmia se llevó a cabo mediante instilación intranasal de una de una solución al $4 \%$ de sulfato de zinc, los días 1 y 3 previos a la realización de cada prueba conductual (De Castro et al., 2010; Martín- López, Puigcerver, Vera \& Navarro, 1993).

\section{Instigación social}

Este procedimiento se realizó con la mitad de los animales aislados y consistió en introducir a un animal instigador en el interior de una jaula cilíndrica con rejilla metálica $(9.5 \times 8 \mathrm{~cm})$, adaptada para nuestro modelo, y situarlo en la jaula del animal aislado. Durante cinco minutos, el animal aislado pudo ver y oler, pero no pudo establecer contacto físico con el animal instigador (Fish et al., 1999). Tras este periodo de instigación, fueron tratados con vehículo o JNJ6259685 y permanecieron 30 minutos en su jaula hasta el momento la interacción agonística. La provocación o instigación social produce incrementos significativos de la conducta agresiva al compararlos con animales que no han sido instigados (De Almeida \& Miczek, 2002; Fish et al., 1999).

\section{Evaluación conductual}

Los encuentros agonísticos entre el animal aislado y el oponente anósmico tuvieron lugar en un área neutral consistente en un recipiente de cristal $(50 \times 26 \times 30 \mathrm{~cm})$, cuya base estaba cubierta de serrín fresco. Ambos animales se situaban en extremos opuestos de la arena durante un periodo de adaptación de 1 minuto y el test conductual (10 minutos) comenzaba al retirar el separador. Todas las pruebas se realizaron bajo una luz roja, a partir de la segunda hora del periodo de oscuridad. Los encuentros fueron grabados en video para su posterior análisis etológico por ordenador (Brain et al., 1989). El análisis de la conducta del animal experimental se realizó de forma "ciega" al tratamiento administrado. Las diez categorías analizadas fueron: 1. Cuidado corporal; 2. Escarbar; 3. Exploración no social; 4. Exploración a distancia; 5. Investigación social; 6. Amenaza; 7. Ataque; 8. Evitación/Huida; 9. Defensa/Sumisión y 10. Inmovilidad (Brain et al., 1989).

\section{Análisis estadístico}

Para comprobar la existencia de diferencias significativas entre los diferentes grupos experimentales se realizó un análisis de la varianza no paramétrico (prueba de Kruskal-Wallis), para cada una de las categorías conductuales evaluadas. Posteriormente, se efectuaron comparaciones entre pares de grupos con la prueba no paramétrica para muestras independientes (prueba U de Mann-Whitney). Se emplearon pruebas no paramétricas al no cumplirse los criterios requeridos para la aplicación de pruebas paramétricas. Para alcanzar la significación estadística se considera como criterio un valor de $<0.05$.

\section{Resultados}

En la Tabla 1 se muestran las medianas (con sus rangos) del tiempo acumulado (en segundos) y de las frecuencias de cada una de las categorías conductuales evaluadas en el encuentro agonístico, así como la latencia del primer ataque. En las categorías conductuales de evitación/huida, defensa/sumisión e inmovilidad, las medianas así como sus rangos fueron igual a cero en todos los caso por lo que no se han incluido en la tabla.

Con la prueba U de Mann-Whitney se pudo constatar que el grupo de animales instigados (Instigación/Vehículo) incrementó el tiempo y la frecuencia con la que realizaban conductas de amenaza y ataque en comparación con el grupo control $(p<0.005)$. Asimismo, la latencia del primer ataque se vio significativamente reducida $(p<$ 0.005) en el grupo de animales instigados. Respecto 
TABLA 1

Medianas (con rangos) de la latencia del primer ataque y tiempo acumulado en segundos (s) y de la frecuencia de cada categoría conductual.

\begin{tabular}{|c|c|c|c|c|c|}
\hline \multicolumn{2}{|l|}{ Categorías Conductuales } & & JNJ & \multicolumn{2}{|c|}{$\begin{array}{c}\text { Instigación } \\
\text { Vehículo JNJ }\end{array}$} \\
\hline Cuidado Corporal $^{\text {a }}$ & $\begin{array}{l}\text { (s) } \\
\text { (f) }\end{array}$ & $\begin{array}{l}7.1(0.4-42) \\
4.5(1-16)\end{array}$ & $\begin{array}{l}2.1(0-20) \\
2(0-7)^{*}\end{array}$ & $\begin{array}{l}9.2(1.5-30)^{*} \\
13(2-25)^{* *}\end{array}$ & $\begin{array}{c}4.3(0-11.7) \# \\
2(0-12) \# \#\end{array}$ \\
\hline Escarbar ${ }^{\mathrm{a}}$ & $\begin{array}{l}\text { (s) } \\
\text { (f) }\end{array}$ & $\begin{array}{l}2.5(0-27) \\
4.5(1-16)\end{array}$ & $\begin{array}{l}0.7(0-6.4) \\
1(0-8) *\end{array}$ & $\begin{aligned} 4.7 & (0.8-23) \\
4 & (1-20)\end{aligned}$ & $\begin{array}{c}2.5(0-10.7) \# \\
2(0-10) \#\end{array}$ \\
\hline Exploración no Social b & $\begin{array}{l}\text { (s) } \\
\text { (f) }\end{array}$ & $\begin{array}{c}365.6(245-442) \\
67(37-88)\end{array}$ & $\begin{array}{c}489(349-545) * * \\
47(10-63) * *\end{array}$ & $\begin{array}{c}352(262-424) \\
67(53-103)\end{array}$ & $\begin{array}{c}476(342-539) \text { \# \# } \\
50(27-69) \text { \# \# }\end{array}$ \\
\hline Exploración a distancia ${ }^{b}$ & $\begin{array}{l}\text { (s) } \\
\text { (f) }\end{array}$ & $\begin{array}{c}4.8(0.8-50.7) \\
5(2-44)\end{array}$ & $\begin{array}{c}3.2(0-11.9) \\
3(0-17) *\end{array}$ & $\begin{array}{c}17.8(1.4-40)^{*} \\
18(2-36)^{*}\end{array}$ & $\begin{array}{c}5.5(0-27) \# \\
6(0-24) \#\end{array}$ \\
\hline Investigación Social a & $\begin{array}{l}\text { (s) } \\
\text { (f) }\end{array}$ & $\begin{array}{c}148.7(35-333) \\
49.5(12-69)\end{array}$ & $\begin{array}{c}93.3(32-225) \\
36(8-55)\end{array}$ & $\begin{array}{l}58(20-186)^{* *} \\
34(12-56)^{*}\end{array}$ & $\begin{array}{c}106(8.6-167) \\
28(12-54)\end{array}$ \\
\hline Amenaza $^{b}$ & $\begin{array}{l}\text { (s) } \\
\text { (f) }\end{array}$ & $\begin{array}{r}18.9(0-152) \\
8.5(0-71)\end{array}$ & $\begin{array}{l}0(0-59.2) * * \\
0(0-22) * *\end{array}$ & $\begin{array}{l}71.5(0-125)^{* * *} \\
35(0-54)^{* *}\end{array}$ & $\begin{array}{l}0(0-89.8) \# \# \\
0(0-49) \# \#\end{array}$ \\
\hline Ataque $^{b}$ & $\begin{array}{l}\text { (s) } \\
(\mathrm{f})\end{array}$ & $\begin{array}{c}7.6(0-71) \\
2(0-34)\end{array}$ & $\begin{array}{l}0(0-29) * \\
0(0-34) *\end{array}$ & $\begin{array}{c}49.5(0-139) * * \\
35(0-54)^{* *}\end{array}$ & $\begin{array}{c}0(0-96.5) \# \# \\
0(0-13) \# \#\end{array}$ \\
\hline Latencia del 1er ataque\#\# & $(\mathrm{s})$ & $523.3(143-600)$ & $600(314-600) *$ & $160(19-600) * *$ & $600(20-600)$ \#\# \\
\hline
\end{tabular}

Prueba de Kruskal-Wallis, ${ }^{a} p<0.05 .{ }^{b} p<0.005$.

Prueba U de Mann-Whitney, comparaciones con grupo Vehículo: $* p<0.05 ; p<* * 0.005$; comparaciones con grupo Instigación/Vehículo: \# $p<0.05$; \# \# $<0.005$

Fuente: elaboración propia

al resto de conductas, los animales del grupo Instigación/Vehículo invertían más tiempo y realizaban las conductas de cuidado corporal y exploración a distancia con más frecuencia $(p<0.05)$ que los animales que no habían sido instigados, mientras que reducían la frecuencia y el tiempo dedicados a las conductas de investigación social $(p<0.05)$.

Por otra parte, los animales tratados con JNJ16259685 redujeron de forma significativa las conductas de amenaza (tiempo acumulado y frecuencia, $p<0.005$ ) y de ataque (tiempo acumulado, $p<0.005$; frecuencia, $p<0.05$ ), e incrementaron la latencia del primer ataque $(<0.05)$, al ser comparados con su grupo control (Vehículo). Igualmente, incrementaron el tiempo dedicado a conductas de exploración no social $(p<0.005)$, aunque redujeron su frecuencia $(p<0.005)$. Por otro lado, redujeron también la frecuencia de las conductas de cuidado corporal, escarbar y exploración a distancia $(p<$ 0.05).

Al comparar los dos grupos que han sido sometidos a instigación (Instigación/Vehículo vs. Instigación/JNJ), se sigue observando que los ani- males tratados con JNJ16259685 reducen de forma significativa las conductas agresivas (frecuencia y tiempo acumulado; $p<0.005)$ y aumentan la latencia del primer ataque $(p<0.005)$. Asimismo, este grupo aumenta el tiempo acumulado ( $p$ $<0.005)$ en exploración no social y reduce su frecuencia. Mientras que las conductas de cuidado corporal, escarbar y exploración a distancia se presentan con menos frecuencia y duración $(p$ $<0.05)$. Por último, no se observan diferencias significativas en ninguna de las categorías conductuales, al comparar el grupo JNJ16259685 con el grupo Instigación/JNJ

\section{Discusión}

En este trabajo se evalúa, por primera vez, la intensificación de la agresión en un modelo de agresión inducida por aislamiento, empleando la instigación social. Igualmente, es el primer estudio que examina la acción del JNJ16259685 (antagonista mGlu1) en un procedimiento de instigación social adaptado al modelo de agresión inducida por aislamiento. 
Los resultados obtenidos demuestran que la instigación social es un procedimiento útil para conseguir intensificar los niveles de agresión obtenidos con el modelo de aislamiento, al reducir drásticamente la latencia de ataque (atacan mucho antes) y aumentar más del doble tanto el tiempo acumulado, como las frecuencias de las conductas de amenaza y ataque evaluadas al comparar a los animales aislados con o sin instigación (Veh vs. Intigación/Vehículo), al igual que lo hace en el modelo de intruso residente (Centenaro et al., 2008; Fish et al., 1999; Miczek et al. 2004).

El modelo de agresión inducida por aislamiento ha sido extensamente empleado en psicofarmacología de la agresión. Permite reproducir conductas agresivas típicas de la especie, adaptativas y dirigidas a competir por un territorio, ya que el aislamiento social incita la agresión normal de un animal territorial como el ratón que se dispersa de su grupo después de llegar a la pubertad (Brain, 1975; Miczek, Yap \& Covington, 2008). Además, permite observar un amplio repertorio de conductas agonísticas, cuando es enfrentado a otro macho de la misma especie por el control de un área neutral, haciendo posible el uso de técnicas etológicas para detectar efectos muy específicos de los fármacos (Olivier \& Van Dalen, 1982).

Por otra parte, la instigación social ha sido utilizada para intensificar la agresión en animales de laboratorio, permitiendo evaluar conductas que exceden los niveles de agresión típicos de la especie y que se caracterizan por presentar "hiperarousal" o "arousal agresivo". En humanos, la violencia afectiva está asociada con altos niveles de "arousal" o activación del sistema nervioso autónomo en respuesta a la percepción de alguna amenaza (Volavka, 2002), y, para algunos autores, este puede ser un modelo útil para el estudio de la agresión impulsiva observada en humanos en el trastorno explosivo intermitente y en la agresión observada en la depresión (Haller \& Kruk, 2006; Miczek, Fish, DeBold \& De Almeida, 2002).

En este trabajo, la provocación social, realizada treinta minutos antes del encuentro agonístico, modifica el repertorio conductual agresivo del animal aislado aumentando las conductas de amenaza y ataque e incrementando la conducta de exploración a distancia, que forman parte de la secuencia del patrón agonístico del animal que generalmente precede a la conducta agresiva; también la conducta de cuidado corporal, que es muy sensible a factores endógenos y exógenos, sugiriéndose como una conducta útil para evaluar los cambios conductuales ante situaciones estresantes (Gómez, Carrasco \& Redolat, 2008), lo que podría estar apoyando la idea de que la instigación hubiese incitado en estos animales un estado de activación agresivo, que les llevaría a incrementar los niveles de agresión.

Es más, si la violencia es considerada como una desviación de la agresión funcional, además del incremento cuantitativo de las conductas agresivas (duración y frecuencia) y de la reducción de la latencia de ataque, debemos considerar otros aspectos destacados por Natarajan, de Vries, Saaltink, de Boer y Koolhaas (2009) como la observación de conductas que forman parte de secuencias agonísticas normales, la adecuación de los ataques a las señales del oponente y la adecuación al contexto. Los animales instigados redujeron a la mitad el tiempo que dedicaban a la investigación social mientras que incrementaron significativamente la amenaza y la fase consumatoria final del ataque, produciendo una descompensación del patrón agonístico que lleva de la investigación del oponente al inicio de las conductas ofensiva. Y, por otra parte, podríamos hablar de conducta desproporcionada o fuera de contexto por producirse ante oponentes anósmicos, que jamás inician ni responden con conductas agresivas, lo que indica que ante las muestras de defensa y sumisión que exhiben los oponentes los animales instigados siguen atacando, alterando así las reglas o rituales específicos de la especie que mantienen la agresión dentro de unos límites funcionales (Haller \& Kruk, 2006). Y, por último, no hay que olvidar que esta agresión se produce en un área neutral, donde diversos estudios constatan unos niveles de agresión muy inferiores a los observados en la propia jaula del animal (Fish et al., 1999).

La administración de JNJ16259685 (0.5 mg/ $\mathrm{kg}$ ) redujo drásticamente las conductas ofensivas (amenaza y ataque), de manera selectiva, sin que este efecto fuera acompañado de incrementos en 
conductas de inmovilidad, replicando trabajos previos (Navarro et al., 2008). Esta potente acción antiagresiva se acompañó de una reducción de las conductas de escarbar, implicadas junto con las conductas de amenaza y ataque en el patrón ofensivo de los ratones agresivos (Kudryavtseva, Bondar \& Alekseyenko, 2000) y de un aumento de la exploración no social, probablemente como conducta compensatoria del tiempo no invertido en la ofensa.

Un resultado especialmente relevante es que el antagonista mGlu1 JNJ16259685 ha mostrado la misma eficacia inhibiendo la agresión intensificada por instigación social, sugiriendo la implicación del receptor mGlu1 en la modulación de formas más extremas de agresión. Es más, aquellas conductas incrementadas por la instigación en el grupo vehículo (cuidado corporal, exploración a distancia, amenaza y ataque), son reducidas tras la administración del fármaco, anulando así el efecto intensificador de la agresión conseguido con la provocación social, incluida también la reducción en la latencia de ataque. Podemos especular por tanto con la posibilidad de que el bloqueo del receptor mGlu1 participe en la reducción del "arousal agresivo" que han mostrado los animales instigados. Estudios recientes ponen de manifiesto que aquellas estructuras relacionadas con el control de la agresión afectiva y de las respuestas al estrés, están sobreactivadas een la agresión por hiperarousal, específicamente la vía que incluye la amígdala medial, hipotálamo mediobasal y sustancia gris periacueductal dorsal (Toth et al., 2012). En estas estructuras se han localizado receptores mGlu1 (Ferraguti \& Shigemoto, 2006), sugiriéndose que la acción ansiolítica descrita con el bloqueo del receptor mGlu1 podría ser específica de situaciones de conflicto, proponiéndose una posible interacción con el sistema GABAérgico en el sistema límbico (Ferraguti, Crepaldi \& Nicoletti, 2008).

Faltan estudios para elucidar el mecanismo de acción por el que el receptor mGlul podría estar modulando la agresión. Sabemos que los antagonistas de los receptores mGlu1 inducen un incremento en la liberación del neurotransmisor GABA y atenúan la función del receptor NMDA en varias regiones cerebrales (Lesage \& Steckler,
2010); igualmente se ha descrito que el bloqueo de los receptores mGlu1 reducen la liberación de dopamina y es conocida la acción antiagresiva de los compuestos antidopaminérgicos (Manzaneque \& Navarro, 1999). Quedaría una tercera opción consistente en estudiar la interacción de este receptor con la actividad de las neuronas serotoninérgicas y los receptores $5 \mathrm{HT}_{1 \mathrm{~A}}$ y $5 \mathrm{HT}_{1 \mathrm{~B}}$ que tanto han sido relacionados con la agresión aumentada con instigación social (Miczek et al., 2013).

En conclusión, en nuestro trabajo se ha evidenciado que el procedimiento de instigación social es capaz de incrementar de forma significativa los niveles de agresión obtenidos con el modelo clásico de agresión inducida por aislamiento, mostrando la posibilidad de emplear esta adaptación para el estudio de formas de agresión más extremas. Y, por otra parte, el compuesto JNJ16259685 ha conseguido reducir de forma específica la conducta agresiva exhibida en ambos modelos, sugiriendo un papel relevante para el receptor metabotrópico mGlu1 en la modulación de la conducta agresiva normal y patológica, lo que abre una nueva línea de investigación sobre las posibilidades terapéuticas en el abordaje de la agresión en humanos.

\section{Referencias}

Antúnez, J. M., Martín-López, M. \& Navarro, J. F. (2011). Modelos animales de agresión patológica. Revista Psiquiatría.com, 15. Recuperado de http:// hdl.handle.net/10401/4799

Belozertseva, I. V. \& Bespalov, A. Y. (1999). Effects of NMDA receptor channel blockade on aggression in isolated male mice. Aggressive Behavior, 25(5), 381-396.

Brain, P. F. (1975).What does individual housing mean to a mouse? Life Sciences, 16, 187-200.

Brain, P. F., McAllister, K. H. \& Walmsey, S. (1989). Drug effects on social behaviour: Methods in ethopharmacology. En A. A. Boulton, G. B. Baker \& A. J. Greenshaws (Eds), Neuromethods (pp. 687-739). New Jersey: Humana Press.

Centenaro, L. A., Vieira, K., Zimmermann, N., Miczek, K. A., Lucion, A. B. \& De Almeida, R. M. M. (2008). Social instigation and aggressive behavior 
in mice: Role of 5-HT1A and 5-HT1B receptors in the prefrontal cortex. Psychopharmacology, 201(2), 237-248.

Comai, S., Tau, M., Pavlovic, Z. \& Gobbi, G. (2012). The psychopharmacology of aggressive behavior: A translational approach. Part 2: Clinical studies using atypical antipsychotics, anticonvulsants, and lithium. Journal of Clinical Psychopharmacology, 32(2), 237-260.

Da Veiga, C. P., Miczek, K. A., Lucion, A. F. \& De Almeida, R. M. M. (2010). Social instigation and aggression in postpartum female rats: Role of 5-HT1A and 5-HT1B receptors in the dorsal raphe nucleus and prefrontal cortex. Psychopharmacology, 213(2), 475-487.

De Almeida, R. M. M. \& Miczek, K. A. (2002). Aggression escalated by social instigation or by discontinuation of reinforcement ("frustration") in mice: Inhibition by anpirtoline: A 5-HT1B receptor agonist. Neuropsychopharmacology, 27(2), 171-181.

De Castro, V., Martín-López, M. \& Navarro, J. F. (2010). Efectos de la administración de LY354740, un agonista selectivo del grupo II de receptores metabotrópicos de glutamato, sobre la conducta agresiva en ratones. Universitas Psychologica, 9(3), 617-625.

Fish, E. W., Faccidomo, S. \& Miczek, K. A. (1999). Aggression heightened by alcohol or social instigation in mice: Reduction by the $5 \mathrm{HT} 1 \mathrm{~B}$ receptor agonist CP-94,253. Psychopharmacology, 146(4), 391-399.

Ferraguti, F. \& Shigemoto, R. (2006). Metabotropic glutamate receptors. Cell and Tissue Research, 326(2), 483-504.

Ferraguti, F., Crepaldi, L. \& Nicoletti, F. (2008). Metabotropic glutamate 1 receptor: Current concepts and perspectives. Pharmacological Reviews, 60(4), 536-581.

Gómez, M. C., Carrasco, M. C. \& Redolat, R. (2008). Differential sensitivity to the effects of nicotine and bupropion in adolescent and adult male OF1 mice during social interaction tests. Aggressive Behavior, 34(4), 369-379.

Haller, J. \& Kruk, M. R. (2006). Normal and abnormal aggression: Human disorders and novel laboratory models. Neuroscience and Biobehavioral Reviews, 30(3), 292-303.
Kudryavtseva, N. N. (1991). A sensory contact model for the study of aggressive and submissive behaviour in male mice. Aggressive Behavior, 17(5), 285-291.

Kudryavtseva, N. N., Bondar, N. P. \& Alekseyenko, O. V. (2000). Behavioral correlates of learned aggression in male mice. Aggressive Behavior, 26(5), 386-400.

Lavreysen, H., Nóbrega, S., Leysen, J. E., Langlois, X. \& Lesage, A. S. J. (2004). Metabotropic glutamate 1 receptor distribution and occupancy in the rat brain: A quantitative autoradiographic study using [3H]R214127. Neuropharmacology, 46(5), 609-619.

Lesage, A. \& Steckler, T. (2010). Metabotropic glutamate mGlu1 receptor stimulation and blockade: Therapeutic opportunities in psychiatric illness. European Journal of Pharmacology, 639(1-3), 2-16.

Manzaneque, J. M. \& Navarro, J. F. (1999). Behavioural profile of amisulpride in agonistic encounters between male mice. Aggressive Behavior, 25(3), 225-232.

Martín-López, M. \& Navarro, J. F. (2002). Antiaggresive effects of zolpidem and zopiclone in agonistic encounters between male mice. Aggressive Behavior, 28(5), 416-425.

Martín-López, M. \& Navarro, J. F. (2009). Papel de las subunidades alfa del receptor $\mathrm{GABA}_{\mathrm{A}}$ en la regulación de la conducta agresiva. Psiquiatría Biológica, 16(4), 167-174.

Martín-López, M., Puigcerver, A., Vera, F. \& Navarro, J. F. (1993). Sulpiride shows an antiaggressive specific effect after acute treatment in male mice. Medical Science Research, 21(16), 595-596.

Miczek, K. A., de Boer, S. F. \& Haller, J. (2013). Excessive aggression as model of violence: A critical evaluation of current preclinical methods. Psychopharmacology, 226(3), 445-458.

Miczek, K. A., Faccidomo, S., De Almeida, R. M. M., Bannai, M., Fish, E. W. \& DeBold, J. F. (2004). Escalated aggressive behavior. New pharmacotherapeutic approaches and opportunities. Annals of the New York Academy of Sciences, 1036(1), 336-355.

Miczek, K. A., Fish, E. W., DeBold, J. F. \& De Almeida, R. M. (2002) Social and neural determinants of aggressive behavior: Pharmacotherapeutic targets at serotonin, dopamine and gamma-amino 
butyric acid systems. Psychopharmacology, 163(34), 434-458.

Miczek, K. A. \& Haney, M. (1994). Psychomotor stimulant effects of D-amphetamine, MDMA and PCPaggressive and schedule-controlled behavior in mice. Psychopharmacology, 115(3), 358-365.

Miczek, K. A., Yap, J. J., \& Covington, H. E. (2008). Social stress, therapeutics and drug abuse: Preclinical models of escalated and depressed intake. Pharmacology 82 Therapeutics, 120(2), 102-128.

Musty, R. E. \& Consroe, P. F. (1982). Phencyclidine produces aggressive behavior in rapid eye movement sleep-deprived rats. Life Sciences, 30, 1733-1738.

Natarajan. D., de Vries, H., Saaltink, D. J., de Boer, S. F. \& Koolhaas, J. M. (2009). Delineation of violence from functional aggression in mice: An ethological approach. Behavior Genetics, 39(1), 73-90.

Navarro, J. F., Burón, E. \& Martín-López, M. (2007). Antiaggressive effects of topiramate in agonistic encounters between male mice. Methods and Findings in Experimental and Clinical Pharmacology, 29(3), 195-198.

Navarro, J. F., De Castro, V. \& Martín-López, M. (2008). JNJ16259685, a selective mGlu1 antagonist, suppresses isolation-induced aggression in male mice. European Journal of Pharmacology, 586(1-3), 217220.

Navarro, J. F., De Castro, V. \& Martín-López, M. (2009). Behavioural profile of selective ligands for mGlu7 and mGlu8 glutamate receptors in agonistic encounters between male mice. Psicothema, 21(3), 475-479.

Navarro, J. F., De Castro, V. \& Martín-López, M. (2010). Papel del glutamato en la regulación de la conducta agresiva en modelos animales. Psiquiatría Biológica, $17(1), 32-36$.

Navarro, J. F., Luque, M. J. \& Martín-López, M. (2009). Effects of LY379268, a selective agonist of mGlu2/3 receptors, on isolation-induced aggression in male mice. The Open Pharmacology Journal, 3, 17-20.
Navarro, J. F., Postigo, D., Martín-López, M. \& Burón, E. (2006). Antiaggressive effects of MPEP, a selective antagonist of $\mathrm{mGlu} 5$ receptor, in agonistic interactions between male mice. European Journal of Pharmacology, 551(1-3), 67-70.

Newman, E. L., Chu, A., Bahamón, B., Takahashi, A., DeBold, J. F. \& Miczek, K. A. (2012). NMDA receptor antagonism: Antagonism: Escalation of aggressive behavior in alcohol-drinking mice. Psychopharmacology, 224(1), 167-177. http://dx.doi. org/10.1007/s00213-012-2734-9

Olivier, B. \& Van Dalen, D. (1982). Social behaviour in rats and mice: An ethologically based model for differentiating psychoactive drugs. Aggressive Behavior, 8(2), 163-168.

Potegal, M. (1992). Time course of aggressive arousal in female hamsters and male rats. Behavioral and Neural Biology, 58(2), 120-124.

Potegal, M. \& Tenbrink, L. (1984). Behavior of attackprimed and attack satiated female golden hamsters (Mesocricetus auratus). Journal of Comparative Psychology, 98(1), 66-75.

Toth, M., Tulogdi, A., Biro, L., Soros, P., Mikics, E. \& Haller, J. (2012). The neural back-ground of hyperemotional aggression induced by post-weaning social isolation. Behavioural Brain Research, 233(1), 120-129.

Vekovischeva, O. Y., Aitta-Aho, T., Echenko, O., Kankaampää, A., Seppäla, T., Honkanen, Sprengel, R., et al. (2004). Reduced aggression in AMPAtype glutamate receptor GluR-A subunit-deficient mice. Genes Brain and Behavior, 3(5), 253-265.

Vekovischeva, O. Y., Aitta-aho, T., Verbitskaya, E., Sandnabba, K. \& Korpi, E. R. (2007). Acute effects of AMPA-type glutamate receptor antagonists on intermale social behavior in two mouse lines bidirectionally selected for offensive aggression. Pharmacology Biochemistry and Behavior, 87(2), 241-249.

Volavka, J. (2002). Neurobiology of violence (2.a ed.). Arlington: American Psychiatric. 
